\title{
57. Production and Chromosomal Features of Triploid Hybrids between Rhodeus ocellatus ocellatus and Acheilognathus limbatus (Cyprinidae, Pisces)*)
}

\author{
By Yoshio OJima, Akinori TAKaI, and Kazuhiro Yamamoto \\ Department of Biology, Faculty of Science, \\ Kwansei Gakuin University, Nishinomiya 662
}

(Communicated by Sajiro Makino, M. J. A., Sept. 12, 1988)

Hybridization experiments in fishes have been carried out by many workers for scientific and practical interests. In these experiments, the spontaneous appearance of the triploidy has been reported by Ojima and Ueda (1978), Ojima et al. (1975), Ueda et al. (1983). On the other hand, since Makino and Ojima (1943) proved cytologically in carp that triploidy can be artificially induced by refrigeration of eggs to prevent the second polar body extrusion, several workers have reported artificial production of triploidy in stickleback (Swarup, 1958), in Tilapia (Valenti, 1975), carp (Ojima and Makino, 1978; Ueno, 1984), Rhodeus ocellatus ocellatus (Ueno and Arimoto, 1982), rainbow trout (Chourrout, 1980 and so on). Interspecific triploid hybrids have been reported only by Purdom (1972).

The present paper deals with the production and chromosomal studies of triploid hybrids between Rhodeus ocellatus ocellatus ( $q$ ) and Acheilognathus limbatus ( $\delta$ ). Several methods, including a new one with the cultured cells of larvae, were used for chromosome preparations. A remarkable feature in the chromosomes of the triploidy is the nucleolar dominance.

Materials and methods. The eggs from Rhodeus ocellatus ocellatus "tairiku-baratanago" were artificially inseminated by sperm from a male of Acheilognathus limbatus "aburabote". Five minutes after the insemination, the eggs were immersed in cold water stabilized at $1-3^{\circ} \mathrm{C}$ for $1 \mathrm{~h}$. After that, the eggs were sterilized by immersing them in $1 / 2$ Dakin's solution, which contains sodium hypochlorite solution (Antiformin) $18 \mathrm{ml}, 1 \mathrm{~N} \mathrm{HCl} 3 \mathrm{ml}$, and $\mathrm{NaHPO}_{3}$ $4 \mathrm{~g}$ per $1 \mathrm{l}$, for $30 \mathrm{sec}$, rinsed with sterilized water three times, and removed to the culture bottles containing sterilized water. The aseptic breeding was continued till the eggs were hatched out and the yolk of the larvae was almost completely absorbed.

Chromosome preparations were made by several methods: a culture method with cells from larvae, a direct method with cells from larvae, the fin culture method (Hayashi et al., 1976; Ojima, 1978), and the direct method with the kidney tissue (Takai and Ojima, 1987). The cell culture method of larvae newly introduced in this study is as follows. A three to seven day old larva, aseptically bred, was rinsed with PBS $(-)$ three times and transferred to a centrifuge tube which included about $1 \mathrm{ml}$ of $0.1 \%$ trypsin solution with $0.01 \% 2 \mathrm{Na} \cdot \mathrm{EDTA}$ and a small magnetic stirrer tip. The centrifuge tube was placed on a magnetic

*) This work was supported by a grant-in-aid (no. 62480071) for the Scientific research from the Ministry of Education, Science and Culture of Japan. 


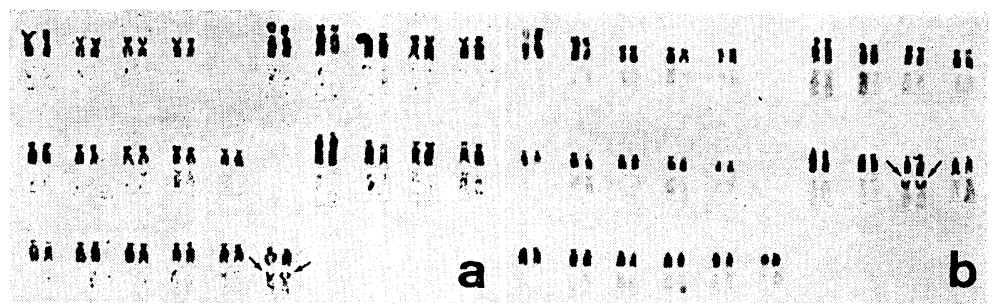

Fig. 1. Conventional and silver staining karyotypes in Rhodeus ocellatus ocellatus (a) and Acheilognathus limbatus (b). Arrows indicate the Ag-NORs.

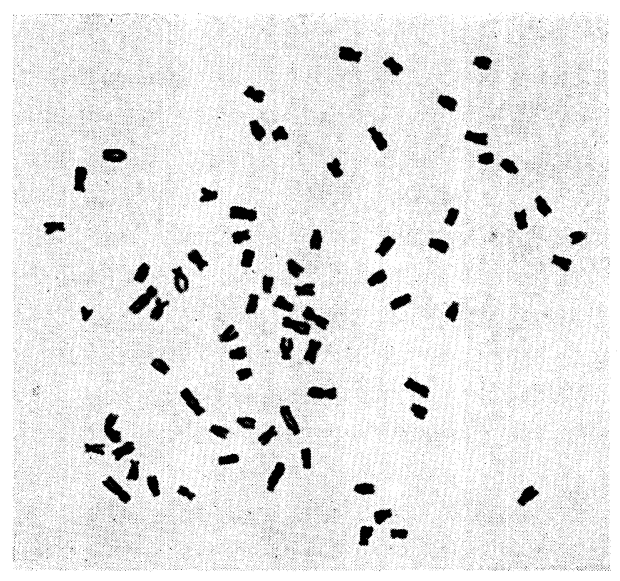

Fig. 2. Metaphase figure of a triploid individual.

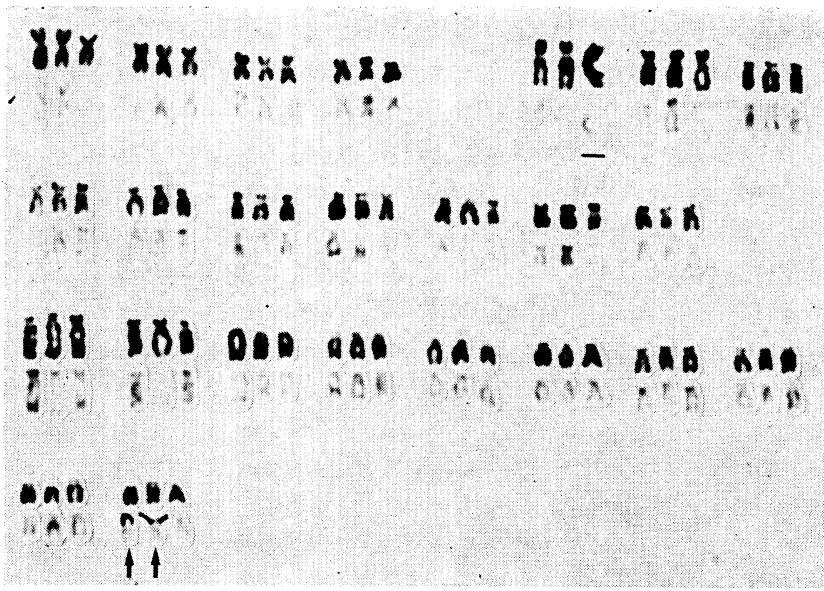

Fig. 3. Karyotype with Ag-NOR staining pattern (lower row) of the triploid individual. Arrows indicate the $\mathrm{Ag}-\mathrm{NORs}$, which are derived from maternal species, Rhodeus ocellatus ocellatus. Bar indicates the largest chromosome from the paternal species, Acheilognathus limbatus. 
stirrer and the sample was stirred for 10-15 min at room temperature. Liberated cells were suspended in $\alpha$-MEM (Flow Lab.) with $10 \%$ fetal bovine serum, transferred to a 24 micro well dish (Flow Lab.), and cultured at $25^{\circ} \mathrm{C}$. The cells obtained from larvae by the same method were also directly treated with colchicine for $2 \mathrm{~h}$ and used for chromosome preparation as a direct method. Chromosome preparations were made from the cells treated with colchicine $(0.1 \mu \mathrm{g} / \mathrm{ml})$ for $2 \mathrm{~h}$ according to the conventional air drying method, and stained with $2 \%$ Giemsa solution. The one-step method (Howell and Black, 1980) was used for silver staining of NORs.

Results and discussion. As shown in Fig. 1, the parental species, Rhodeus ocellatus ocellatus and Acheilognathus limbatus, have the same chromosome number of $2 n=48$ and their karyotypes are very similar to each other (Ojima et al., 1973). The only apparent difference between the two species is the morphology of the largest chromosomes, which is submetacentric in $R$. o. ocellatus and metacentric in A. limbatus (Takai and Ojima, 1986).

All of seven specimens from the treated eggs were the triploidy with the chromosome number of 72 (Fig. 2). The karyotype of the triploids consisted of four sets of metacentrics, ten sets of submetacentrics, and ten sets of acrocentrics, each of which comprised three morphologically identical or similar chromosomes (Fig. 3). In the largest submetacentric set, one member was metacentric that differed from the other two members. Thus, the result of the karyotype analysis clearly reflected the morphologic difference of the largest chromosomes between the parental species and showed that the karyotype consisted of two haploid sets of $R$. o. ocellatus and a haploid set of A. limbatus, suggesting that the triploidy resulted from the prevention of the second polar body by the cold shock as was shown by Makino and Ojima (1943) and Ojima and Makino (1978).

Silver stained nucleolus organizer regions (Ag-NORs) were found in the secondary constrictions of the short arms of the two smallest acrocentric chromosomes (Fig. 3). Rhodeus ocellatus ocellatus has NORs in the smallest acrocentric pair but Acheilognathus limbatus has them in the third chromosome pair as was shown by Takai and Ojima (1986) (Fig. 1). Therefore, it is clear that the Ag-NORs in the triploid hybrids appeared in the NOR-bearing chromosomes derived from $R$. o. ocellatus. This result also suggests that the genome of the triploid hybrid contains a diploid set of maternal species. No NOR from $A$. limbatus, however, was detected by the silver technique. In interphase nuclei, Ag-stained nucleoli varied from one to two.

The phenomenon that in interspecific hybrids transcriptional activity of the rDNA derived from one species is suppressed, is known as nucleolar dominance. Nucleolar dominance in animals has been reported in Xenopus (Honjo and Reeder, 1973; Cassidy and Blackler, 1974), Drosophia (Durica and Krider, 1977), lizard (Ward and Cole, 1986), and mammalian somatic cell hybrids (D. A. Miller et al., 1976; O. J. Miller et al., 1976). In fish hybrids, the NORs of carp-funa hybrids were studied but did not show the nucleolar dominance (Takai and Ojima, 1982). In the triploid hybrid between $R$. o. ocellatus ( $q$ ) and A. limbatus ( $\hat{o}$ ) in this study, the two NORs from maternal species were active but that from paternal species was inactive. This probably resulted from the nucleolar dominance. Recently, we also found that in the diploid hybrid between the same species only one NOR from maternal species were stained by the silver (unpublished). It is of interest whether the suppression of NORs in these hybrids 
cccurs only in the NORs derived from the paternal species, or by other reciprocal relations. Two molecular mechanisms of nucleolar dominance are proposed (Reeder, 1985). It is interesting to speculate whether such mechanisms function in the nucleolar dominance in these hybrids. Fifteen species of Rhodeinae are known in Japan (Nakamura, 1969). Further studies on usual diploid and triploid hybrids between the different species of this subfamily including reciprocal cross should give interesting results.

The aseptic breeding introduced in this study was very effective not only to prevent the failure by contamination in the cell culture of larvae but also to decrease the death rate in the early developmental stage. Also, the cell culture method with larvae will be used as a very available method to examine exactly chromosomes as soon as possible after artificial production of polyploidy and so on.

Summary. Triploid hybrids between Rhodeus ocellatus ocellatus (female) and Acheilognathus limbatus (male) were artificially induced by cold shock treatment of eggs for $1 \mathrm{~h}, 5 \mathrm{~min}$ after the insemination. All of the treated eggs examined so far were triploidy. The chromosome number of the triploids was 72 , and their karyotype consisted of a diploid set of the maternal species and a haploid set of the paternal species. When silver staining was applied, only NORs from the maternal species ( $R$. o. ocellatus) were stained deeply; no NOR from the paternal species was detected. The aseptic breeding and the cell culture method with larvae newly induced in this study were very useful for facilitating breeding and chromosome studies.

Acknowledgments. We are grateful to Dr. Sajiro Makino, M. J. A., Emeritus Professor, Hokkaido University, and Dr. J. R. Miller, Takeda Chemical Industry Co. Ltd., for going over the manuscript and giving invaluable advice.

\section{References}

Cassidy, D. M., and Blackler, A. W. (1974): Dev. Bicl., 41, 84-86.

Chourrout, D. (1980): Reprod. Nutr. Develop., 20, 727-733.

Durica, D. S., and Krider, H. M. (1977) : Dev. Biol., 59, 62-74.

Hayashi, M., Ojima, Y., and Asano, N. (1976) : Jpn. J. Genet., 51, 65-68.

Honjo, T., and Reeder, R. H. (1973) : J. Mol. Biol., 80, 217-228.

Howell, W. M., and Black, D. A. (1980) : Experientia, 36, 1014-1015.

Makino, S., and Ojima, Y. (1943): Cytologia, 13, 56-60.

Miller, D. A. et al. (1976) : Exp. Cell Res., 101, 235-243.

Miller, O. J. et al. (1976) : Proc. Nat. Acad. Sci. USA, 73, 4531-4535.

Nakamura, M. (1969) : Cyprinid Fishes of Japan. Special Publ. Res. Inst. Nat. Reso, no. 4, pp.1-455 (in Japanese).

Ojima, Y. (1982): The Nucleus, 25, 1-7.

Ojima, Y., and Makino, S. (1978): Proc. Japan Acad., 54B, 359-362.

Ojima, Y., and Ueda, T. (1978): ibid., 54B, 15-20.

Ojima, Y., Hayashi, M., and Ueno, K. (1975): ibid., 51, 702-706.

Ojima, Y., Ueno, K., and Hayashi, M. (1973) : Zool. Mag., 82, 171-177.

Reeder, R. H. (1985) : J. Cell Biol., 101, 2013-2016.

Purdom, C. E. (1972) : Heredity, 29, 11-24.

Swarup, H. (1958) : J. Genet., 56, 129-160.

Takai, A., and Ojima, Y. (1982): Proc. Japan Acad., 58B, 303-306.

- (1986): Proc. Second International Conf. Indo-Pacific Fish., pp. 867-876. (1987) : Proc. Japan Acad., 63B, 17-20.

Ueda, T. et al. (1983): Bull. Jpn. Soc. Sci. Fish., 50, 1331-1336.

Ueno, K. (1984) : Jpn. J. Genet., 59, 585-591.

Ueno, K., and Arimoto, B. (1982) : Experientia, 38, 544-546.

Valenti, R. J. (1975): J. Fish Biol., 7, 519-528.

Ward, O. G., and Cole, C. J. (1986): Cytogenet. Cell Genet., 42, 177-182. 